\title{
Comparison of the Effects of Magnesium Sulfate and Remifentanil on Hemodynamic Responses During Tracheal Extubation After Laparotomy: A Randomized Double-blinded Trial
}

\author{
Seyed Mojtaba Marashi ${ }^{1}$; Reza Hassan Nikkhouei ${ }^{1}$; Ali Movafegh ${ }^{1}$; Gita Shoeibi ${ }^{1}$; Shaqayeq \\ Marashi $^{1, *}$ \\ ${ }^{1}$ Anesthesiology Department, Shariati Hospital, Tehran University of Medical Sciences, Tehran, Iran \\ ${ }^{*}$ Corresponding author: Shaqayeq Marashi, Anesthesiology Department, Tehran University of Medical Sciences, Tehran, Iran. Tel: +98-9123257790, Fax: +98-2177568809, \\ E-mail:shm1377@yahoo.com \\ Received: November 11, 2014; Revised: February 15, 2015; Accepted: April 12, 2015
}

\begin{abstract}
Background: Because blood pressure and heart rate (HR) elevations during tracheal extubation are common, different medications have been studied to prevent such complications.

Objectives: To compare magnesium sulfate, remifentanil, and placebo regarding mean arterial pressure (MAP) and HR changes during/ after tracheal extubation, in patients who underwent laparotomy.

Materials and Methods: In this randomized double-blinded trial, 120 patients undergoing laparotomy were evenly divided into three groups, including remifentanil ( $1 \mathrm{mcg} / \mathrm{kg}$ ), magnesium sulfate $(50 \mathrm{mg} / \mathrm{kg}$ ), or normal saline, as placebo. Hemodynamic responses (MAP and HR) were documented at different times (before operation, during medication administration, immediately before extubation, immediately after extubation, and also 3, 5, and 10 minutes after extubation). The double burst time (DBT) was determined using neuromuscular monitoring, as time interval, between administration of reverse medication and DBT of $100 \%$.

Results: The HR was significantly lower, immediately after extubation and 3, 5, and 10 minutes after extubation, in both magnesium and remifentanil groups, compared to normal saline $(\mathrm{P}<0.001)$. The MAP was also lower in magnesium and remifentanil groups, immediately after extubation and 3 minutes after extubation, in comparison to the normal saline group $(\mathrm{P}<0.001)$. Mean $( \pm$ SD) DBT $100 \%$ was significantly higher in magnesium group (30.2 \pm 15.3$)$ vs. remifenatnil $(13.6 \pm 6.8)$ and normal saline $(13.5 \pm 8.2)$ groups $(\mathrm{P}<0.001)$.

Conclusions: Both remifentanil and magnesium had favorable outcomes in preventing HR and MAP elevation after tracheal extubation. However, remifentanil was associated with more rapid regaining of consciousness and reversal of muscular relaxation.
\end{abstract}

Keywords: Remifentanil; Magnesium; Blood Pressure; Heart

\section{Background}

Tracheal extubation is an important part of general anesthesia, which can be associated with complications (1). Both cardiac and respiratory complications, associated with tracheal extubation, may lead to considerable morbidity and mortality (2). Cardiopulmonary adverse events resulted from tracheal extubation (12.6\%) are three times more common when compared to those of endotracheal intubation and induction of general anesthesia $(4.6 \%)(3)$.

The major adverse events associated with tracheal extubation include mechanical complications (such as trauma to the larynx) (4), cardiovascular complications [such as $10-30 \%$ increase in blood pressure (BP) and heart rate (HR) increase for 5-10 minutes] (5), respiratory complications (atelectasis, coughing, hypoxia and etc.) (6).

Documented beneficial effects of magnesium, as a selective blocker for calcium channels and N-methyl-d-aspartate (NMDA) receptor antagonist, have been the basis for multiple studies that have reported protective effects of this medication regarding hemodynamic responses, in patients undergoing general anesthesia $(7,8)$. Studies have noted that magnesium has an important role as vasodilator in arterioles, whereas this effect is minimal on venules, which result in improvement in cardiac output (9). This function is regulated mainly by blocking sympathetic system via inhibiting the release of catecholamines from the adrenal, as well as peripheral nerve endings (10). In addition, magnesium has beneficial effects on maintaining diastolic function and regulating sinus rhythm, during arrhythmias (11). Since magnesium is a vasodilator, it has been used in general anesthesia to decrease BP and prevent its elevation.

Remifentanil, as an anilidopiperidine opioid, has similar pharmacodynamic characteristics to other opioids, however with distinct pharmacokinetic properties (12). This is an effective medication for analgesia, considering its analgesic properties. Since it has no inhibitory effect on the local nervous system, it can be used during extuba-

Copyright (C) 2015, Iranian Society of Regional Anesthesia and Pain Medicine(ISRAPM). This is an open-access article distributed under the terms of the Creative Commons Attribution-NonCommercial 4.0 International License (http://creativecommons.org/licenses/by-nc/4.0/) which permits copy and redistribute the material just in noncommercial usages, provided the original work is properly cited. 
tion (13). In comparison to fentanyl and alfentanil, remifentanil administration is associated with better control of hemodynamic responses during surgery and lower rate of respiratory depression. However, hypotension and bradycardia have been reported, when remifentanil is administered during surgery, and its effects, after extubation, are not completely understood (14).

As mentioned earlier, hemodynamic changes during extubation are common. Hence, medications have been used to prevent these unfavorable changes. Magnesium sulfate and remifentanil are two of the medications that may be used, although studies to determine their efficacy in this regard, as well as any other side effects resulted by using these agents are necessary.

\section{Objectives}

Here, we intended to compare the effects of remifentanil and magnesium on BP, as well as heart rate changes during tracheal extubation, in patients undergoing laparotomy under general anesthesia.

\section{Materials and Methods}

This was a randomized double-blinded clinical trial. The study population consisted of patients who were candidates for laparotomy at our university hospital. Inclusion criteria consisted of age range between 18 and 55 years, ASA (American society of anesthesiologists) class I or II, laparotomy duration of less than 2 hours, no background medical conditions, including cardiovascular diseases, neuromuscular diseases, acute or chronic renal diseases, no dependence to narcotic drugs, and lack of history of taking anti-hypertensive or anti-arrhythmic medications. Exclusion criteria were prolongation of general anesthesia (more than 2 hours), a significant hemodynamic instability, which necessitates medical intervention, or development of arrhythmias, which required medical intervention. The study protocol was approved by the ethics committee of our university. The study steps were described for the patients and written informed consent was obtained from them, prior to participation. All data were kept confidential and the patients were not charged for the study purposes. The study protocol was in conformity with the ethical guidelines of the 1975 Declaration of Helsinki (15).

A total of 120 patients were included. The patients were randomly divided (using random number table, computer-based) into three groups: remifentanil (40 cases), magnesium sulfate (40 cases), and normal saline (as placebo) (40 cases). Upon admission to the operation room, $\mathrm{HR}$, systolic BP (SBP), diastolic BP (DBP) and mean arterial pressure (MAP) were documented and were used as baseline hemodynamic data of the subjects. Then, all patients underwent noninvasive intraoperative blood pressure (NIBP), bispectral index (BIS), ECG, and pulse oximetry monitoring. Then, standard general anesthesia, which was used for all patients, was initiated, as follow: first, fentanyl ( $2 \mathrm{mcg} / \mathrm{kg}$ ) and midazolam ( $0.03 \mathrm{mg} / \mathrm{kg}$ ) were injected intravenously. Then, for anesthesia induction, thiopental sodium ( $5 \mathrm{mg} / \mathrm{kg}$ ) was injected and for facilitation of endotracheal intubation, atracurium $(0.5 \mathrm{mg} / \mathrm{kg})$ was injected. Three minutes after administering atracurium, tracheal intubation was done via direct laryngoscopy. In order to continue the general anesthesia, isoflurane gas at 0.5 - 1.5 MAC (minimum alveolar concentration) was used to keep MAP at about $10 \%$ of the baseline value. Capnography monitoring was attached for all patients and end-tidal CO2 was kept at 35 - $45 \mathrm{mmHg}$, with control of the respiratory rate. During the operation, atracurium ( $0.15 \mathrm{mg} / \mathrm{kg})$ and fentanyl $(0.7 \mathrm{mcg} / \mathrm{kg})$ were injected every 30 minutes. The SBP, DBP and MAP were recorded by automatic oscillometric BP devices. The HR was recorded by ECG. The BIS range was kept at 40 - 50. The volume of intravenous (IV) fluids, necessary for patients, was calculated according to the weight, maintenance fluid, deficit fluid, and volume of bleeding and was replaced by lactated Ringer's solution or normal saline.

The last stitch on the skin placed by the surgeon was considered as the last painful stimulus of the surgery (time 0). At this time, magnesium sulfate $(50 \mathrm{mg} / \mathrm{kg})$, or with the same volume remifentanil ( $1 \mathrm{mcg} / \mathrm{kg})$, or the same volume of normal saline were administered for the three groups of the study. The injected medications had similar volumes and were prepared in similar syringes. The syringes were numbered and the technician who injected the medications was unaware of the medications. The patients remained on ventilator with $100 \%$ oxygen. When, based on muscular monitoring, train-of-four (TOF) became 2 of 4 (50\%), atracurium effect was reversed, using neostigmine $(0.04 \mathrm{mg} / \mathrm{kg})$ and atropine $(0.02 \mathrm{mg} /$ $\mathrm{kg}$ ). When the patient opened his/her eye spontaneously or showed purposeful movements, extubation was done. The variables recorded were gender, age, weight, operation duration, fentanyl dosage used, the time of the last dose of fentanyl, the time interval between medication administration and extubation and DBT, using neuromuscular monitoring, as the time interval between administration of reverse medication and DBT of $100 \%$. The hemodynamic variables of interest, including SBP, DBP, and HR were recorded at time 0 , immediately before tracheal extubation, immediately after extubation, and 3, 5, and 10 minutes after extubation. Coughing at 1 minute before and 1 minute after extubation was documented and its severity was categorized as mild ( 1 - 2 coughs), moderate ( 3 - 5 coughs), and severe (> 5 coughs). At 5 and 15 minutes after extubation, consciousness level was recorded based on the sedation score scale, using the following indices:

1. Alert and responsive

2. Drowsy, although responsive to verbal command

3. Unresponsive to verbal command

To report continuous data, mean \pm standard deviation (SD) was used. Categorical data were reported by frequency and percentage. To compare categorical variables be- 
Marashi SM et al.

tween the three groups, the Chi-squared test or the Fisher's exact test were applied. Continuous variables were compared between the groups via analysis of variance (ANOVA) or Kruskal-Wallis test, depending on the normal distribution of the data, determined by the KolmogorovSmirnov test. To investigate the changes of the studied variables, at different time points, repeated measure ANOVA was used. The significance level was set at 0.05. All analyses were performed with the SPSS software for Windows (ver. 20.0) (IBM, New York, NY, USA).

\section{Results}

Table 1 presents the baseline characteristics (age, gender, weight) of the patients. As shown, no significant differences were found, regarding baseline characteristics, between the three groups.

Table 2 presents anesthesia-related variables. As shown, no significant differences were found regarding mean general anesthesia duration, total fentanyl dosage ad- ministered, time interval passed between fentanyl administration and studied medication administration, or time interval between studied medication administration and tracheal extubation, between the three groups. Regarding HR changes, recorded before starting the operation until 10 minutes after extubation, there was no significant difference between the three groups, until the time point recorded immediately before extubation. However, immediately after extubation and 3, 5, and 10 minutes after extubation, mean HR showed a significant decrease, in comparison to normal saline group (Table 3). However, analysis of the HR changes pattern, at different time points, showed that there was no significant difference between the groups, with respect to heart rate during follow-up period $(\mathrm{P}=0.11)$.

A similar pattern to HR changes was observed with regard to MAP.At follow-up time point before extubation, no significant difference was seen between the two groups. However, MAP was significantly lower in remifentanil and

Table 1. Comparison of Age, Gender, and Weight in Laparotomy Patients who Received Remifentanil, Magnesium Sulfate, or Normal Saline ${ }^{\mathrm{a}}$

\begin{tabular}{lcccc}
\hline & Remifentanil & Magnesium Sulfate & Normal Saline & P Value \\
\hline Gender, Male & $52.5 \%$ & $45 \%$ & $47.5 \%$ & 0.79 \\
Age, $\mathbf{y}$ & $43( \pm 11.7)$ & $42.7( \pm 10.5)$ & $38.7( \pm 12.7)$ & 0.18 \\
Weight, $\mathbf{~ k g}$ & $66.4( \pm 10.8)$ & $68.4( \pm 8.9)$ & $70.6( \pm 10.2)$ & 0.17 \\
\hline
\end{tabular}

a For each group: $(\mathrm{n}=40)$.

Table 2. Comparison of General Anesthesia-Related Variables in Laparotomy Patients who Received Remifentanil, Magnesium Sulfate, or Normal Saline ${ }^{\text {a }}$

\begin{tabular}{|c|c|c|c|c|}
\hline & Remifentanil & Magnesium Sulfate & Normal Saline & PValue \\
\hline Anesthesia Duration, min & $108.4( \pm 18.6)$ & $108.9( \pm 11.8)$ & $106.7( \pm 10.5)$ & 0.77 \\
\hline Total Fentanyl Dosage, mcg & $275( \pm 45.3)$ & $278( \pm 51.7)$ & $261.2( \pm 57.1)$ & 0.28 \\
\hline $\begin{array}{l}\text { Time Interval Between Fentanyl and Studied Medication } \\
\text { Administration, min }\end{array}$ & $25.7( \pm 16.9)$ & $33.9( \pm 15.4)$ & $31( \pm 19.70)$ & 0.1 \\
\hline $\begin{array}{l}\text { Time Interval Between Studied Medication Administra- } \\
\text { tion and Tracheal Extubation, min }\end{array}$ & $16.4( \pm 8)$ & $14.45( \pm 3.1)$ & $14.9( \pm 4.9)$ & 0.26 \\
\hline
\end{tabular}

Table 3. Comparison of Mean ( \pm SD) Heart Rate at Different Time Points in Patients who Underwent Laparotomy and Received Remifentanil, Magnesium Sulfate, or Normal Saline ${ }^{\text {a }}$

\begin{tabular}{|c|c|c|c|c|}
\hline & Remifentanil & Magnesium Sulfate & Normal Saline & PValue \\
\hline Before Operation & $93.4( \pm 17.6)$ & $87.6( \pm 15.6)$ & $90.2( \pm 14.3)$ & 0.26 \\
\hline Time $0^{b}$ & $79.2( \pm 10.9)$ & $81.2( \pm 15.8)$ & $78.7( \pm 14.7)$ & 0.7 \\
\hline Immediately Before Extubation & $93.8( \pm 17.3)$ & $98.2( \pm 14.9)$ & $94.9( \pm 14.9)$ & 0.74 \\
\hline Immediately After Extubation & $95.4( \pm 10.6)$ & $105.2( \pm 16.4)$ & $111.03( \pm 14.9)$ & $<0.001$ \\
\hline Minute 3 Post-Extubation & $85.2( \pm 12.3)$ & $85.9( \pm 17.8)$ & $98.05( \pm 13)$ & $<0.001$ \\
\hline Minute 5 Post-Extubation & $85.06( \pm 12.8)$ & $85.2( \pm 15.2)$ & $92.8( \pm 11.7)$ & $<0.001$ \\
\hline Minute 10 Post-Extubation & $84.7( \pm 12.8)$ & $85.7( \pm 13.9)$ & $91.9( \pm 12.1)$ & $<0.001$ \\
\hline
\end{tabular}

\footnotetext{
a For each group: $(n=40)$

$\mathrm{b}$ Time $0=$ after putting the last stitch on the skin.
} 
Marashi SM et al.

Table 4. Comparison of Mean ( \pm SD) Mean Arterial Pressure (MAP) at Different Time Points in Patients Underwent Laparotomy Who Received Remifentanil, Magnesium Sulfate, or Normal Saline ${ }^{\text {a }}$

\begin{tabular}{lcccc}
\hline & Remifentanil & Magnesium Sulfate & Normal Saline & P Value \\
\hline Before Operation $^{\prime}$ & $102.6( \pm 16.7)$ & $100.2( \pm 17.08)$ & $102.7( \pm 10.6)$ & 0.69 \\
Time 0 $^{\text {b }}$ & $94.3( \pm 17.2)$ & $98.8( \pm 11.4)$ & $92.7( \pm 10.8)$ & 0.11 \\
\hline Immediately Before Extubation $^{\prime}$ & $101.08( \pm 14.6)$ & $103.1( \pm 19.9)$ & $97.05( \pm 13.7)$ & 0.23 \\
Immediately After Extubation & $104.9( \pm 18.6)$ & $107.1( \pm 9.9)$ & $119.1( \pm 11.02)$ & $<0.001$ \\
Minute 3 Post-Extubation & $105( \pm 11.2)$ & $101.4( \pm 8.5)$ & $111.08( \pm 15.1)$ & 0.002 \\
\hline Minute 5 Post-Extubation & $102.2( \pm 9.6)$ & $100.1( \pm 9.1)$ & $100.7( \pm 11.2)$ & 0.63 \\
Minute 10 Post-Extubation & $99.8( \pm 8.54)$ & $98.9( \pm 9.05)$ & $98.9( \pm 11.01)$ & 0.88 \\
\hline
\end{tabular}

a For each group: $(\mathrm{n}=40)$.

$\mathrm{b}$ Time $0=$ after putting the last stitch on the skin.

magnesium groups, compared to normal saline group, immediately after extubation, as well as at minute 3 after extubation. At minutes 5 and 10 post-extubation, again no difference was present between the groups. Two groups of remifentanil and magnesium were comparable regarding MAP changes (Table 4). Analysis of MAP changes pattern, at different time points, showed that there was no significant difference between the groups during follow-up period $(\mathrm{P}=0.58)$.

Remifentanil and magnesium, both resulted in less severe coughing episodes, compared to normal saline. The frequencies of mild and moderate coughing were $82.5 \%$ and $10 \%$ in remifentanil group, $80 \%$ and $20 \%$ in magnesium group, and $40 \%$ and $52.5 \%$ in normal saline group, respectively. Severe cough was not reported in magnesium group, although it was reported in $7.5 \%$ of patients of normal saline and remifentanil groups $(\mathrm{P}<0.001)$. However, no difference was detected between magnesium and remifentanil groups.

At 5 minutes after extubation, $60 \%$ of normal saline cases were alert and responsive; however, this percentage was $47.5 \%$ in remifentanil group and $25 \%$ in magnesium group $(P=0.004)$. Similar findings were noted at 15 minutes postextubation time. Alertness and responsiveness was reported in $95 \%$ of normal saline patients, $72.5 \%$ of remifenatnil cases and in $60 \%$ of magnesium patients $(\mathrm{P}=0.007)$.

Mean \pm SD DBT $100 \%$ was significantly higher in magnesium group (30.2 \pm 15.3$)$ vs. remifenatnil $(13.6 \pm 6.8)$ and normal saline $(13.5 \pm 8.2)$ groups $(\mathrm{P}<0.001)$.

\section{Discussion}

This study aimed to compare magnesium and remifentanil regarding their effects on hemodynamic responses during tracheal extubation, in patients undergoing laparotomy. The obtained findings showed that mean HR recorded a significant decrease, in both magnesium and remifentanil group, immediately after tracheal extubation. This trend continued until 10 minutes post-extubation. Likewise, MAP was significantly lower in magnesium and remifentanil groups, compared to normal saline group, after extubation. This continued just up to 3 minutes post-extubation, and then the three groups were similar regarding MAP. When the two groups of magnesium and remifentanil are compared, we did not detect differences between them in terms of HR or MAP. Administering magnesium and remifentanil, both resulted in less severe coughing episodes, in comparison to normal saline, although neither magnesium nor remifentanil had superiority to each other in decreasing coughing severity. However, regarding consciousness level, the patients who received just normal saline had higher rate of alertness and responsiveness at 5 and 15 minutes postextubation than patients of remifentanil or magnesium groups.

The above core findings suggest that both magnesium and remifentanil have comparable effects on hemodynamic responses during and shortly after tracheal extubation. However, patients of remifentanil group had a better profile in regaining consciousness than magnesium group.

In a similar clinical trial, the effects of remifentanil (1 $\mathrm{mcg} / \mathrm{kg}$ ) or magnesium sulfate $(30 \mathrm{mg} / \mathrm{kg}$ ) were compared versus placebo, regarding SBP, DBP, HR and oxygen saturation in electroconvulsive therapy (7). The authors studied 20 patients for whom anesthesia was induced by thiopental ( $4 \mathrm{mg} / \mathrm{kg}$ ). They reported that remifentanil and magnesium administration were associated with a significant attenuation of the increase in SBP. However, only remifentanil attenuated $\mathrm{HR}$, not magnesium. It was concluded that, since magnesium had no effect on HR, this effect may be considered as an advantage, compared to remifentanil, in patients who needed electroconvulsive therapy. These findings are similar to ours, in terms of BP changes, as we observed that both remifentanil and magnesium prevented increases in MAP. Plus, we observed a similar effect on HR, which was not reported by the mentioned article in magnesium group. The advantage of magnesium is attributed to the fact that it may result in bradycardia, and similarly, we did not see bradycardia in our patients who received magnesium or remifentanil.

In a study to determine the hemodynamic responses after endotracheal intubation, magnesium sulfate and remifentanil were compared. Lim et al. (16) studied 80 
patients who underwent general anesthesia and divided them to receive normal saline, magnesium sulfate (50 $\mathrm{mg} / \mathrm{kg}$ ), remifentanil ( $1 \mathrm{mcg} / \mathrm{kg})$, or a combination of 25 $\mathrm{mg} / \mathrm{kg}$ magnesium sulfate and $0.5 \mathrm{mcg} / \mathrm{kg}$ remifentanil, which were administered half a minute before induction of anesthesia, with propofol and succinylcholine. The results showed that SBP changes of patients, who received magnesium, remifentanil, or combination of these two agents, were lower, immediately after intubation than those of the normal saline group. The SBP in magnesium and magnesium/remifentanil groups showed an increase in relation to baseline recording, although SBP alone, in remifentanil group, decreased from that at the baseline, immediately after intubation. In contrast to our results, where we observed a decrease in HR in both remifentanil and magnesium groups, Lim et al. found an increase in HR of magnesium group, with a decrease of heart rate in remifentanil group. They concluded that magnesium was associated with increase in SBP and tachycardia after intubation, whereas remifentanil resulted in SBP drop and bradycardia (16).

Kim et al. (17) studied remifentanil infusion effects on hemodynamic responses and coughing during extubation in postoperative (major abdominal surgery) intensive care unit patients, in a randomized clinical trial. They reported that MAP, HR and coughing severity did not differ between the two groups during extubation. The only significant difference was related to the time from discontinuation of propofol infusion to extubation, which was significantly longer in the remifentanil group, compared to control group. Wu et al. (18) investigated the efficacy of different dosages of remifentanil (0.05, 0.1, and $0.2 \mathrm{mcg} / \mathrm{kg}$ ) for attenuating cardiovascular response to tracheal extubation, after general anesthesia, in 164 surgical (upper abdominal surgery) patients. They concluded that remifentanil at $0.1 \mathrm{mcg} / \mathrm{kg}$ was the ideal dose to prevent hemodynamic response to tracheal extubation.

As the prevention of MAP and HR elevation, after tracheal extubation, is considered in anesthesiology, both magnesium and remifentanil had comparable effects in prevention of adverse hemodynamic responses. Regarding the faster regaining of consciousness and reversal of muscular relaxation, remifentanil was superior to magnesium. Future studies can focus on different dosages of magnesium and remifentanil, as well as using longer post-operation follow-ups.

\section{Authors' Contributions}

Seyed Mojtaba Marashi: designing the study and collecting data, supervising. Nikkhouie: literature review, data collection, Movafegh: interpreting data and statistics analysis Shoeibi: Approving the final manuscript, data collection. Shaqayeq Marashi: manuscript preparation, final revision, manuscript approval.

\section{Funding/Support}

A grant paid by Tehran university of medical sciences, Tehran, Iran.

\section{References}

1. Artime CA, Hagberg CA. Tracheal extubation. Respir Care. 2014;59(6):991-1002.

2. Cavallone LF, Vannucci A. Review article: Extubation of the difficult airway and extubation failure. Anesth Analg. 2013;116(2):36883.

3. Asai T, Koga K, Vaughan RS. Respiratory complications associated with tracheal intubation and extubation. Br J Anaesth. 1998;80(6):767-75.

4. Rassam S, Sandbythomas M, Vaughan RS, Hall JE. Airway management before, during and after extubation: a survey of practice in the United Kingdom and Ireland. Anaesthesia. 2005;60(10):9951001.

5. Miller KA, Harkin CP, Bailey PL. Postoperative tracheal extubation. Anesth Analg. 1995;80(1):149-72.

6. Magnusson L, Spahn DR. New concepts of atelectasis during general anaesthesia. BrJAnaesth. 2003;91(1):61-72.

7. van Zijl DH, Gordon PC, James MF. The comparative effects of remifentanil or magnesium sulfate versus placebo on attenuating the hemodynamic responses after electroconvulsive therapy. Anesth Analg. 2005;101(6):1651-5.

8. Dube L, Granry JC. The therapeutic use of magnesium in anesthesiology, intensive care and emergency medicine: a review. Can J Anaesth. 2003;50(7):732-46.

9. Prielipp RC, Zaloga GP, Butterworth J, Robertie PG, Dudas LM, Black KW, et al. Magnesium inhibits the hypertensive but not the cardiotonic actions of low-dose epinephrine. Anesthesiology. 1991;74(6):973-9.

10. Shariat Moharari R, Motalebi M, Najafi A, Zamani MM, Imani F, Etezadi F, et al. Magnesium Can Decrease Postoperative Physiological Ileus and Postoperative Pain in Major non Laparoscopic Gastrointestinal Surgeries: A Randomized Controlled Trial. Anesth Pain Med. 2014;4(1):e12750.

11. Mayer DB, Miletich DJ, Feld JM, Albrecht RF. The effects of magnesium salts on the duration of epinephrine-induced ventricular tachyarrhythmias in anesthetized rats. Anesthesiology. 1989;71(6):923-8.

12. Beers R, Camporesi E. Remifentanil update: clinical science and utility. CNS Drugs. 2004;18(15):1085-104.

13. Michelsen LC. The pharmakokionetics of remifentanil. J Clin Anesth. 1996;8:679-82.

14. Scholz J, Steinfath M. [Is remifentanil an ideal opioid for anesthesiologic management in the 21st century?]. Anasthesiol Intensivmed Notfallmed Schmerzther.1996;31(10):592-607.

15. Smith T.Ethics in medical research.Cambridge: Cambridge University Press;1990. p. 12-49.

16. Lim SH, An DG, Choi SW, Lee SE, Kim YH, Lee JH, et al. The Comparison of Magnesium Sulfate and Remifentanil in Attenuating Hemodynamic Response to Endotracheal Intubation. Korean J Anesthesiol. 2007;53(5):577-82.

17. Kim SY, Yang SY, Na SW, Jo YY, Koh SO. Low-dose remifentanil infusion during ventilator weaning and tracheal extubation in postoperative intensive care unit patients sedated with propofolremifentanil: a randomised clinical trial. Anaesth Intensive Care. 2012;40(4):656-62.

18. Wu J, Liu L, Yang F. [Effect of small-dose remifentanil on cardiovascular response to tracheal extubation after general anesthesia]. Nan Fang Yi Ke Da Xue Xue Bao. 2012;32(9):1316-8. 